\section{Predictive factor for successful retrograde ureteral stent insertion in obstructive uropathy due to advanced cervical cancer}

\author{
Bambang Sasongko Noegroho, \\ Akhmad Mustafa \\ Department of Urology, Hasan Sadikin \\ Hospital, Bandung, Indonesia
}

\begin{abstract}
Cervical cancer is the $3^{\text {rd }}$ most common cancer in women. Some of the patients came with kidney failure due to malignant ureteral obstruction. Retrograde ureteral stent insertion as palliative urinary diversion often performed on these patients, but it has high failure rate and often has to be converted to nephrostomy, giving the patient unnecessary burden due to failed procedure. In this study, we evaluate factors that may predict successful ureteral stenting in cervical cancer patients to avoid unnecessary burden to the patient. Data were collected from 2014-2017. We evaluate the clinical, ultrasound and laboratory findings before stent insertion of the patient with successful compared to failed insertion. Comparative study was done using independent T-test and Mann-Whitney U test for nonparametric data. Odds ratio (OR) were calculated using contingency table and $\mathrm{P}$ value calculated using Fisher exact test. There were 41 patients diagnosed with cervical cancer performed retrograde ureteral stenting. From 41 patients, $20(48.7 \%)$ were successful and $21(51.3 \%)$ failed. Low hydronephrosis grade $(\mathrm{OR}=85.8 ; \mathrm{P}<0.0001)$, low stage $(\mathrm{OR}=6.0 ; \mathrm{P}=0.0098)$, radiotherapy $(\mathrm{OR}=3.7$; $\mathrm{P}=0.04$ ) were strong predictor for successful stent insertion. In bilateral hydronephrosis, more daily urine output $(\mathrm{OR}=29.2 ; \mathrm{P}=0.002)$ and normal creatinine level $(\mathrm{OR}=6.3$; $\mathrm{P}=0.03$ ) were strong predictors for successful retrograde stenting, while bladder infiltration was strong predictor for stent failure $(\mathrm{OR}=0.0684 ; \mathrm{P}=0.0021)$. Low hydronephrosis grade, no bladder infiltration, normal creatinine level, more daily urine output, low clinical staging and radiotherapy are predictive factors to predict a successful ureteral stenting in cervical cancer patients.
\end{abstract}

\section{Introduction}

Cancer of the uterine cervix is the $3^{\text {rd }}$ most common gynecologic cancer diagnosis and cause of death among gynecologic cancers worldwide. In the world, there were approximately 500.000 new cases of cervical cancer diagnosed and approximately 250.000 cases of death found for each year. ${ }^{1}$ In developing countries including in Indonesia, cervical cancer has higher incidence than developed countries. ${ }^{2}$ In Indonesia, about 20,928 new cervical cancer cases are diagnosed annually (estimations for 2012). ${ }^{3}$ Cervical cancer ranks as the $2^{\text {nd }}$ leading cause of female cancer and the $2^{\text {nd }}$ most common female cancer in women aged 15 to 44 years. ${ }^{3}$ Most patients $(66.4 \%)$ came in advanced disease (stage $2 \mathrm{~b}-4 \mathrm{~b})$ according to the International Federation of Gynecology and Obstetrics (FIGO) and $37.3 \%$ in stage $3 \mathrm{~b}$ (with obstructive uropathy). ${ }^{4}$ The cases present in advanced stages of the disease with associated poor prognosis and high mortality rates. ${ }^{4}$ In many of them, it is difficult to offer definitive treatment as they present in uremia due to associated obstructive uropathy. This is due to either external compression or malignant involvement of lower ureters. These patients may have large primary advanced/recurrent/post treatment progressive residual disease.

Ureteral obstruction due to malignancy carries a poor prognosis with a resulting median survival of 3-7 months and hence most patients are treated with best supportive care or some palliative diversion procedure. ${ }^{5}$ A study by Rasjidi showed a significant longer survival in patients with advanced cervical cancer who underwent percutaneous nephrostomy, even though the median survival was only 203 days. $^{6}$ Another study by Lapitan et al. showed there was no evidence of an impact on quality of life and the decision to offer diversion surgery might be based solely on a survival benefit, ${ }^{7}$ which is modest but potentially important to patients to able them continue their treatment and spent their time with their family. Various method of urinary diversion could be used for palliative urinary diversion. The most common and simple method is percutaneous nephrostomy (PCN). ${ }^{8}$ Other methods including the use of various material of ureteral stents. ${ }^{9}$ Both procedures has its own advantages and disadvantages. Sometimes ureteral stent insertion failed due to unidentified ureteral opening on cystoscopy and has to be converted to PCN. Even though, endoscopic ureteral stent placement is a simple and safe procedure that can be done under local anesthesia, it may give some burden to the patients including painful procedure and hematuria. ${ }^{10}$ Moreover, in some hospital retrograde ureteral stent insertion was done under regional or even general anesthesia, it burdens the patients with impaired renal
Correspondence: Akhmad Mustafa, Department of Urology, Hasan Sadikin Hospital, Jl. Cikutra Baru Permai no 28A. 40124, Bandung, Indonesia.

E-mail: mustafa.urologi@gmail.com

Key words: Cervical cancer; Predictive factors; Ureteral stenting.

Contributions: BSN: study design; AM: data collection, manuscript writing.

Conflict of interest: the authors declare no potential conflict of interest.

Funding: none.

Received for publication: 2 June 2018.

Revision received: 1 February 2019.

Accepted for publication: 21 March 2019.

This work is licensed under a Creative Commons Attribution NonCommercial 4.0 License (CC BY-NC 4.0).

CCopyright B.S. Noegroho and A. Mustafa, 2019

Licensee PAGEPress, Italy

Urogynaecologia 2019; 31:221

doi:10.4081/uij.2019.221

function and could be avoided if we carefully selected the patients. In this study, we attempt to evaluate factors that may predict successful retrograde ureteral stenting in advanced cervical cancer patients in order to reduce unnecessary PCN conversion in retrograde ureteral stenting.

\section{Materials and Methods}

The design of this study is observational analytics with cross sectional study. This study was approved by Hasan Sadikin Hospital Institutional Review Board for ethical clearance. All patients with attempted retrograde ureteral stenting, either successful or failed, with bilateral or unilateral hydronephrosis were included as subjects. Ureteral stent insertion was done under regional anesthesia. Cystoscopy was done using 20 Fr rigid cystoscope and $30^{\circ}$ optic lens to identify the ureteral opening. When the ureteral opening identified but stenosis present, ureterorenoscopy then performed to assist guidewire and Double J (DJ) stent insertion. Hydrophilic guidewire then inserted and DJ stent inserted using sliding technique. The procedure was failed if the ureteral opening cannot be identified or either the guidewire or the stent cannot be inserted.

Data included were based on ultrasound findings before stent insertion: Degree of 
hydronephrosis, diameter of retrovesical mass and presence of bladder infiltration on ultrasound. Laboratory findings including pre-diversion blood urea nitrogen (BUN) and creatinine level. Clinical findings including clinical stage according to FIGO criteria, daily urine production and previous history of chemoradiation or surgery.

Grade of hydronephrosis was classified according to the Society of Fetal Ultrasound (SFU). ${ }^{11}$ We compared the daily urine production, BUN and creatinine level only in patients with bilateral obstruction, with assumption for patients with unilateral obstruction, the unobstructed kidney will biased the urine production, BUN and creatinine level to normal.

We separated the subjects as 2 groups: Those with successful retrograde ureteral stent insertion (group I) and those with failed retrograde ureteral stent insertion attempt (group II). Comparative study was performed using independent T-test for normally distributed parametric data Alternatively, we used Mann-Withney U test for non-parametric data or parametric data that not normally distributed. We calculated the odd ratios (ORs) of every significantly different characteristic between the two groups using Fisher exact test with 95\% confidence intervals (CIs). With calculated OR we hope to find the most reliable predictive factor to predict the successful or failure in DJ stent insertion. The data were analyzed using SPSS version 21.0 for Windows.

\section{Results}

We performed retrograde ureteral stenting attempt in 41 patients, either bilateral or unilateral hydronephrosis. Retrograde ureteral stenting was successful in 20 patients $(48.7 \%)$, and failed in 21 patients $(51.3 \%)$ and converted to PCN. The mean age of group I was $49.9 \pm 8.34$ years, and Group II was $47.7 \pm 8.33$ years. There was no significant difference between mean age of both groups $(\mathrm{P}=0.427)$. The reason of failure retrograde stenting was unidentified ureteral opening in 18 cases $(85.7 \%)$ and unable to slide the guide wire due to severe stenosis in 3 patients $(14.3 \%)$ (Table 1$)$.

\section{Ultrasound findings}

We evaluate the severity of hydronephrosis from ultrasonographic finding of both groups. Hydronephrosis grading was classified according to SFU. In group I, we found the majority of hydronephrosis grade were grade 1 and grade 2, compared to failed stenting group that had a majority of grade 3 and grade 4 hydronephrosis. Using Mann-whitney U test, we found that the hydronephrosis grade was significantly higher in group II than in group I $(\mathrm{P}<0.0001)$ (Table 1, Figure 1).

We also identify the retrovesical mass diameter and presence of suspicious bladder infiltration. In group I, the mean mass diameter were $2.38 \pm 1.75 \mathrm{~cm}$, with 6 subjects $(30 \%)$ has no mass infiltration detected. In group II the mean mass diameter were $5.28 \pm 1.70 \mathrm{~cm}$. Using independent T-test, we found a significant higher retrovesical mass diameter in group II than in group I
$(\mathrm{P}<0.0001)$. We found only 2 patients with suspicious bladder infiltration on ultrasound also found significant difference in incidence of suspected bladder infiltration between successful stenting group compared to failed stenting group $(2(10 \%) v s$ 13(61.9\%); $\mathrm{P}=0.001$ ) (Table 1).

\section{Laboratory findings}

We compared the BUN and creatinine level between group I and group II with bilateral hydronephrosis, with assumption in subjects with unilateral hydronephrosis, the contralateral unobstructed kidney will

\section{Hydronephrosis Grade}

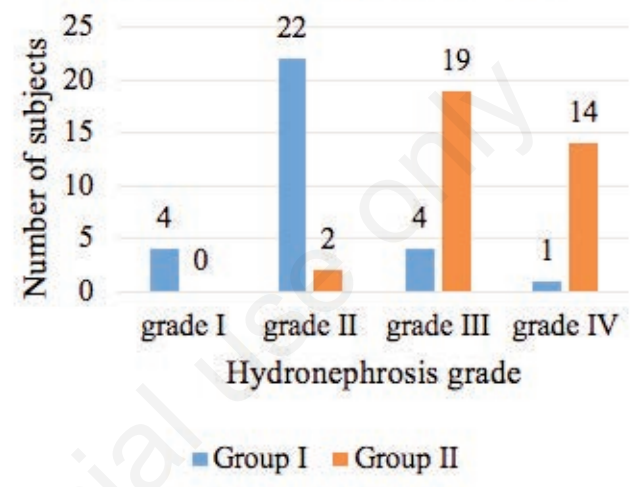

Figure 1. Comparison of hydronephrosis grade.

Table 1. Patient characteristics.

\begin{tabular}{|c|c|c|c|}
\hline & $\begin{array}{c}\text { Success (group I) } \\
n=20\end{array}$ & $\begin{array}{c}\text { Failed (group II) } \\
n=21\end{array}$ & P value \\
\hline Age & $49.9 \pm 8.34$ & $47.7 \pm 8.33$ & $0.427^{\mathrm{a}}$ \\
\hline $\begin{array}{l}\text { Stenting attempt } \\
\text { Unilateral } \\
\text { Bilateral }\end{array}$ & $\begin{array}{l}10(50 \%) \\
10(50 \%)\end{array}$ & $\begin{array}{l}7(33.3 \%) \\
14(66.7 \%)\end{array}$ & \\
\hline $\begin{array}{l}\text { Ultrasound findings } \\
\text { Hydronephrosis } \\
\text { Grade I } \\
\text { Grade II } \\
\text { Grade III } \\
\text { Grade IV } \\
\text { Mass diameter }\end{array}$ & $\begin{array}{c}4(12.9 \%) \\
22(70.9 \%) \\
4(12.9 \%) \\
1(3.2 \%) \\
2.38 \pm 1.75\end{array}$ & $\begin{array}{c}0(0 \%) \\
2(5.7 \%) \\
19(54.2 \%) \\
14(40 \%) \\
5.28 \pm 1.70\end{array}$ & $\begin{array}{l}<0.0001^{\mathrm{b}} \\
<0.0001^{\mathrm{b}}\end{array}$ \\
\hline $\begin{array}{l}\text { Presence of bladder infiltration } \\
\text { Yes } \\
\text { No }\end{array}$ & $\begin{array}{c}n=20 \\
2(10 \%) \\
18(90 \%)\end{array}$ & $\begin{array}{c}n=21 \\
13(61.9 \%) \\
8(38.1 \%)\end{array}$ & $0.001^{\mathrm{b}}$ \\
\hline $\begin{array}{l}\text { Laboratory findings } \\
\text { Blood urea nitrogen level (bilateral) } \\
\text { Creatinine (bilateral) } \\
\text { Staging (FIGO) } \\
\text { Stage } 3^{\mathrm{b}} \\
\text { Stage } 4\end{array}$ & $\begin{array}{l}41.3 \pm 24.68 \\
2.5 \pm 1.98 \\
n=20 \\
15(75 \%) \\
5(25 \%)\end{array}$ & $\begin{array}{l}143.9 \pm 72.1 \\
9.4 \pm 4.53 \\
n=21 \\
7(33.3 \%) \\
14(66.7 \%)\end{array}$ & $\begin{array}{l}0.004^{\mathrm{a}} \\
0.001^{\mathrm{a}} \\
0.016^{\mathrm{b}}\end{array}$ \\
\hline $\begin{array}{l}\text { Previous therapy } \\
\text { Previous surgery } \\
\text { Previous chemotherapy } \\
\text { Previous radiotherapy } \\
\text { Clinical findings } \\
\text { Urine production (bilateral) }\end{array}$ & $\begin{array}{c}2(10 \%) \\
2(10 \%) \\
13(65 \%) \\
n=10 \\
1470 \pm 494.2\end{array}$ & $\begin{array}{c}1(4.76 \%) \\
2(9.5 \%) \\
7(33.3 \%) \\
n=14 \\
673 \pm 343.3\end{array}$ & $<0.0001^{\mathrm{a}}$ \\
\hline
\end{tabular}

andependent T-test; ${ }^{\mathrm{B}}$ Mann-Withney U test. FIGO, International Federation of Gynecology and Obstetrics. 
compensate the BUN and creatinine level to normal or near normal value. There were 10 subjects in group I with bilateral hydronephrosis with mean BUN level of $41.3 \pm 24.68 \mathrm{mg} / \mathrm{dl}$ and 14 subjects in group II with mean BUN level of $143.9 \pm 72.1$ $\mathrm{mg} / \mathrm{dl}$. The mean creatinine level in group I was $2.5 \pm 1.98 \mathrm{mg} / \mathrm{dl}$, while in group II was $9.4 \pm 4.53 \mathrm{mg} / \mathrm{dl}$. Using independent T-test, we found a significant difference between BUN level and creatinine level of the two groups $(\mathrm{P}=0.004 ; \mathrm{P}=0.001)$ (Table 1$)$.

\section{Clinical findings}

We evaluate urine production of the subjects with bilateral hydronephrosis, with assumption, in unilateral hydronephrosis patients, the contralateral kidney will compensate the function of obstructed kidney. In group I $(n=10)$ the mean daily urine production was $1470 \pm 494.2 \mathrm{ml} / 24$ hours, while in group II the mean urine production was $673 \pm 343.3 \mathrm{ml} / 24$ hours. Using independent T-test, we found a significantly higher daily urine production in group I compared to group II $(\mathrm{P}<0.0001)$ (Table 1).

We compared the clinical staging of the subjects using FIGO classification. The staging was made primarily based on physical examination and ultrasound findings by our colleagues from Gynaecology Department. We found in group I the predominant clinical staging was stage $3 \mathrm{~b}$ (75\%) followed by stage $4(25 \%)$ while in group II, the predominant clinical stage was stage $4(66.7 \%)$ followed by stage $3 b$ (33.3\%). Using Mann-Whitney U test, we found a significant difference between the two groups $(\mathrm{P}=0.016)$ (Table 1, Figure 2).

We also compared the history of previous therapy of the subjects and divide as previous mass excision surgery (bilateral hystero-salphingo-ovarectomy), radiotherapy and chemotherapy. In group I we found 14 subjects $(70 \%)$ with previous therapy consists of surgery in $2(10 \%)$, chemotherapy in $2(10 \%)$ and radiotherapy in $13(65 \%)$. In group II, we found 7 subjects $(33.3 \%)$ with previous therapy, consists of surgery in $1(4.76 \%)$ subject, chemotherapy in 2 (9.5\%), and radiotherapy in $7(33.3 \%)$ patients. Using Mann-Whitney U test, we found no significant difference between the 2 groups $(\mathrm{P}=0.769)$ (Table 1, Figure 3$)$.

\section{Risk analysis for successful stent insertion}

Using Fisher Exact test, we analyzed the odd ratio of each variable. In ultrasound findings, we found lower hydronephrosis grade as a strong predictor for successful retrograde ureteral stent insertion $(\mathrm{OR}=85,8$; $\mathrm{P}<0.0001 ; \mathrm{CI}=15.39-478.45)$ and presence of bladder infiltration as a strong predictor for failed ureteral stent insertion (OR=0.0684; $\mathrm{P}=0.0021 ; \quad \mathrm{CI}=0.012-0.378)$. From laboratory findings, we found normal BUN level (women $<20 \mathrm{mg} / \mathrm{dl}$ ) was not significant as a predictor for successful stent insertion $(\mathrm{OR}=4.0 ; \mathrm{P}=0.073 ; \mathrm{CI}=0.88-18.2)$, while normal creatinine level $(0.6-1.1 \mathrm{mg} / \mathrm{dl})$ was a strong predictor for successful stent insertion $(\mathrm{OR}=6.3 ; \mathrm{P}=0.03 ; \mathrm{CI}=1.146-35.0)$.
From clinical findings, we found daily urine production of more than $1000 \mathrm{ml}$ in bilateral hydronephrosis patients $(\mathrm{OR}=29.2 ; \mathrm{P}=0.002$; $\mathrm{CI}=3.45-247.7)$, lower clinical staging (stage $3 \mathrm{~b}$ according to $\mathrm{FIGO})(\mathrm{OR}=6.0 ; \mathrm{P}=0.0098$; $\mathrm{CI}=1.54-23.3)$ and history of complete radiotherapy $(\mathrm{OR}=3.7 ; \mathrm{P}=0.04 ; \mathrm{CI}=1.021-13.51)$ as a strong predictor for successful stent insertion (Table 2).

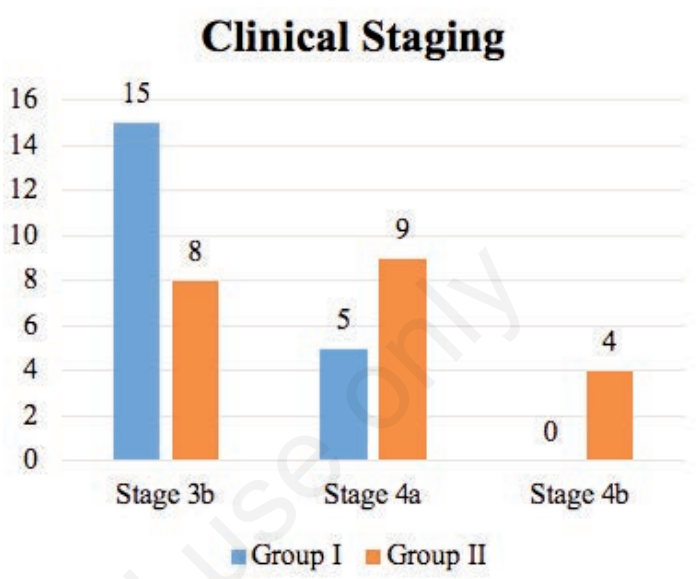

Figure 2. Cervical cancer clinical staging.

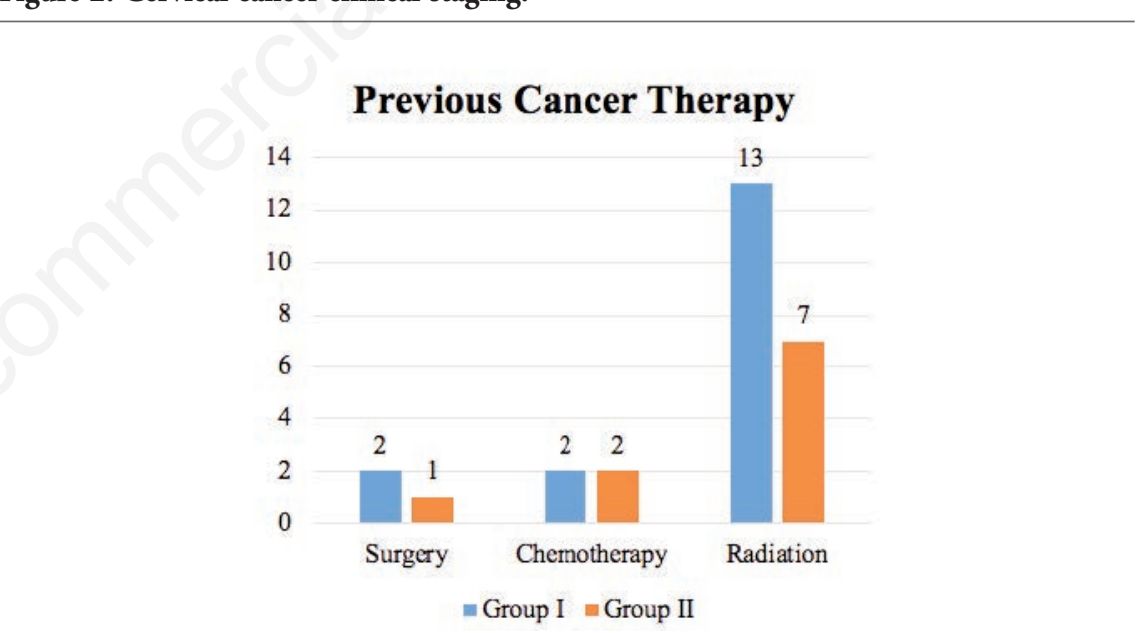

Figure 3. Previous cancer therapy.

Table 2. Risk analysis of successful retrograde stent insertion.

\begin{tabular}{lccc} 
& P-value & OR & $95 \%$ CI \\
Ultrasound findings & & & \\
$\quad$ Lower hydronephrosis grade & $<0.0001$ & 85.8 & $15.39-478.45$ \\
Presence of bladder infiltration & 0.0021 & 0.0684 & $0.012-0.378$ \\
$\quad$ Mass diameter & $<0.0001$ & - & - \\
Laboratory findings & & & \\
Blood urea nitrogen & 0.073 & 4.0 & $0.88-18.2$ \\
Creatinine & 0.03 & 6.3 & $1.146-35.0$ \\
\hline Clinical findings & & & \\
Daily urine production & 0.002 & 29.2 & $3.45-247.7$ \\
Lower clinical staging & 0.0098 & 6.0 & $1.54-23.3$ \\
Previous radiotherapy & 0.04 & 3.7 & $1.021-13.51$ \\
\hline
\end{tabular}

$\mathrm{OR}$, odd ratio; $\mathrm{CI}$, confidence interval. 
will result in decrease of bilateral renal blood flow and glomerular filtration rate. ${ }^{19,20}$ This mechanism will cause elevation of BUN and creatinine level and also reduce the daily urine production, as seen in patient with bilateral hydronephrosis in this study. Unfortunately, various factors influence the BUN and creatinine level other than the obstruction such as dehydration, presence of sepsis condition, history of diabetic and hypertensive renal disease and intrinsic renal disease..$^{21,22}$

There are two criterion for the diagnosis of Stage $3 b$ carcinoma of the uterine cervix in the current FIGO staging system: the tumor fixed to the pelvic side wall or the presence of hydronephrosis not explainable by other factors. ${ }^{23}$ Stage 4 of cervical cancer defined as the tumor invades mucosa of bladder or rectum and/or extends beyond true pelvis. ${ }^{21}$ In this study, clinical staging according to FIGO criteria in successful stent insertion was significantly lower than in failed group. Bladder infiltration in stage 4 cervical cancer found in 13 patients in this study, while the other 1 included in stage 4 due to distant metastasis. In a study by Wang et al., bladder wall invasion was a significant predictive factor for stent failure. ${ }^{16}$ Jeong et al. reviewed the use of ureteric stents placed for 86 patients with a malignant ureteral obstruction and found that $13(15 \%)$ experienced failure of retrograde stent insertion, and that the risk of failure for stent insertion significantly increased with the presence of bladder invasion. ${ }^{24}$ Ganatra and Loughlin analyzed 157 patients with malignant ureteral obstruction who underwent retrograde ureteral stent placement, and found that when invasion into the bladder was noted on cystoscopy, $55.9 \%$ developed stent failure. ${ }^{25}$

In previous study by Wang et al., prior radiotherapy was shown to be associated with insertion failure on univariate analysis. However, multivariate analysis failed to confirm prior radiotherapy as an independent risk factor for stent insertion failure. ${ }^{16}$ On the contrary with study by Wang et al., in our study prior radiotherapy present as predictive factor for successful stent insertion in cervical cancer patients. This may related to effect of radiotherapy to shrink the tumor mass that compress the ureter. ${ }^{26}$

Our study did have certain limitations. The study population was retrospectively enrolled from a single center in Indonesia. The sample number was too small to represent the general population in Indonesia and too small for multivariate analysis to be done. Our Hospital was teaching hospital so the stent insertion procedure was done by different surgeon with different experience that can interfere with the success rate of the procedure. In the future, a prospective study should enroll a larger number of patients to determine more precise predictive factors and a scoring should be made to ensure no unnecessary cystoscopy and stent attempt in cervical cancer patients.

\section{Conclusions}

From this study, we could conclude that patient with lower hydronephrosis grade, normal creatinine level, lower clinical stage, history of complete radiation and daily urine production more than $1000 \mathrm{cc}$ in 24 hours most likely to be successful in DJ stent placement while patient with bladder infiltration from ultrasound will be not suitable for DJ stent placement candidate. With the use of predictive factor that could predict retrograde stenting successfulness, we could carefully select the patient to reduce the failure rate and avoid unnecessary burden of cystoscopy, failed stenting attempt and anesthesia.

\section{References}

1. Jemal A, Bray F, Center MM, et al. Global cancer statistics. CA Cancer J Clin 2011;61:69-90.

2. World Health Organization (WHO). Comprehensive Cervical Cancer Control. Geneva, WHO; 2006.

3. Bruni L, Barrionuevo-Rosas L, Albero $\mathrm{G}$, et al. ICO Information Centre on HPV and Cancer (HPV Information Centre). Human Papillomavirus and Related Diseases in Indonesia. Summary Report 27 July 2017. Available from: https://www.hpvcentre.net/statistics/reports/XSX.pdf

4. Rasjidi I. Epidemiologi Kanker Serviks. Ind J Canc 2009;3:103-8.

5. Kouba E, Wallen EM, Pruthi RS. Management of ureteral obstruction due to advanced malignancy: optimizing therapeutic and palliative outcomes. J Urol 2008;180:444-50.

6. Rasjidi I, Gunawan A, Susanto C. Effect of percutaneous nephrostomy in late stage cervical cancer's survival with impaired renal function. Majalah Obstetr Ginekol 2016;24:49-52.

7. Lapitan MCM, Buckley BS. Impact of palliative urinary diversion by percutaneous nephrostomy drainage and ureteral stenting among patients with advanced cervical cancer and obstructive uropathy: A prospective cohort. J Obstet Gynaecol Res 2011;37:1061-70. 8. Soper JT, Blaszczyk TM, Oke E, et al. 
Percutaneous nephrostomy in gynecologic oncology patients. Am J Obstet Gynecol 1988;158:1126-31.

9. Chung HH, Kim JY, Won JH, et al. Multicenter experience of the newly designed covered metallic ureteral stent for malignant ureteral occlusion: comparison with double $\mathrm{J}$ stent insertion. Cardiovasc Interv Radiol 2013;37:46370.

10. Carrouget J, Ammi M, Lasocki S, et al. Double-J ureteral stent under local anesthesia for women. Can J Urol 2014;21:7120-4.

11. Fernbach SK, Maizels M, Conway JJ. Ultrasound grading of hydronephrosis: introduction to the system used by the Society for Fetal Urology. Pediatr Radiol 1993;23:478-80.

12. Shekarriz B, Shekarriz H, Uphadyay J, et al. Outcome of palliative urinary diversion in the treatment of advanced malignancies. Am Canc Soc 1999;85:4.

13. Ganatra AM, Loughlin KR. The management of malignant ureteral obstruction treated with ureteral stents. J Urol 2005;174:2125-8.

14. Pedamallu R, Subramanian S. Factors predicting success rate of retrograde ureteric stenting in managing patients with ureteric obstruction - our experiences in a South Indian Tertiary Institute. Internet J Urol 2015;14:1.

15. Yossepowitch O, Lifshitz DA, Dekel Y, et al. Predicting the success of retrograde stenting for managing ureteral obstruction. J Urol 2001;166:1746-9.

16. Wang JY, Zhang HL, Zhu Y, et al. Predicting the failure of retrograde ureteral stent insertion for managing malignant ureteral obstruction in outpatients. Oncol Letter 2016;11:879-83.

17. Yamagami T, Ide K, Nishio K. Studies on the pathophysiology of ureteral lesion in treatment for the uterine cervical cancer. Kurume Med J 1973;20:1138.

18. Castle WN, McDougall S. Contralateral renal hyperplasia and increased renal function after relief of chronic unilateral ureteral obstruction. J Urol 1984;132:1016-20.

19. Siegel NJ, Feldman RA, Lytton B, et al. Renal cortical blood flow distribution in obstructive nephropathy in rats. Circ Res 1977;40:379-84.

20. Gulmi FA, Matthews GJ, Marion D, et al. Volume expansion enhances the recovery of renal function and prolongs the diuresis and natriuresis after release of bilateral ureteral obstruction: a possible role for atrial natriuretic peptide. J Urol 1995;153:1276-83.

21. Higgins C. Urea and the clinical value measuring blood urea concentration. Available from: www.acutecaretesting.org Accessed: July 2016.

22. Baum N, Dichoso CC, Carlton CE. Blood urea nitrogen and serum creatinine. Urology 1975;5:583-8.

23. Sobin LH, Wittekind L. TNM Classification of malignant tumours. UICC International Union Against Cancer. 6th ed. Hoboken NJ: Wiley; 2002. 155-157.

24. Jeong IG, Han KS, Joung JY, et al. The outcome with ureteric stents for managing non urological malignant ureteric obstruction. BJU Int 2007;100:1288-91.

25. Ganatra AM, Loughlin KR. The management of malignant ureteral obstruction treated with ureteral stents. J Urol 2005; 174:2125-8

26. Jacinto AA, Castilho MS, Novaes P, et al. Preoperative external beam radiotherapy and reduced dose brachytherapy for carcinoma of the cervix: survival and pathological response. Radiat Oncol 2007;2:9. 